\title{
Olfactory Bulb External Tufted Cells Are Synchronized by Multiple Intraglomerular Mechanisms
}

\author{
Abdallah Hayar, ${ }^{1}$ Michael T. Shipley, ${ }^{2}$ and Matthew Ennis ${ }^{1}$ \\ ${ }^{1}$ Department of Anatomy and Neurobiology, University of Tennessee Health Science Center, Memphis, Tennessee 38163, and ${ }^{2}$ Department of Anatomy and \\ Neurobiology, Program in Neuroscience, University of Maryland, Baltimore, Maryland 21201
}

In rat olfactory bulb slices, external tufted (ET) cells spontaneously generate spike bursts. Only ET cells affiliated with the same glomerulus exhibit significant synchronous activity, suggesting that synchrony results mainly from intraglomerular interactions. The intraglomerular mechanisms underlying their synchrony are unknown. Using dual extracellular and patch-clamp recordings from ET cell pairs of the same glomerulus, we found that the bursting of ET cells is synchronized by several mechanisms. First, ET cell pairs of the same glomerulus receive spontaneous synchronous fast excitatory synaptic input that can also be evoked by olfactory nerve stimulation. Second, they exhibit correlated spontaneous slow excitatory synaptic currents that can also be evoked by stimulation of the external plexiform layer. These slow currents may reflect the repetitive release of glutamate via spillover from the dendritic tufts of other ET or mitral/tufted cells affiliated with the same glomerulus. Third, ET cells exhibit correlated bursts of inhibitory synaptic activity immediately after the synchronous fast excitatory input. These bursts of IPSCs were eliminated by CNQX and may therefore reflect correlated feedback inhibition from periglomerular cells that are driven by ET cell spike bursts. Fourth, in the presence of fast synaptic blockers, ET cell pairs exhibit synchronous slow membrane current oscillations associated with rhythmic spikelets, which were sensitive to the gap junction blocker carbenoxolone. These findings suggest that coordinated synaptic transmission and gap junction coupling synchronize the spontaneous bursting of ET cells of the same glomerulus.

Key words: external tufted; bursting; dual recordings; coefficient of correlation; IPSCs; synchrony

\section{Introduction}

Oscillations or cycling discharges of neurons operate as pacemakers or timing devices for various kinds of information processing (for review, see Singer, 1999; Laurent, 2002). Neuronal oscillators rarely operate at fixed frequencies. Rather, their frequency is generally regulated by synaptic input (the visual cortex, Lestienne, 1999; the subiculum, Menendez de la Prida, 2003). In olfactory bulb slices, external tufted (ET) cells exhibit synchronous spontaneous spike bursting that persists and, indeed, becomes more regular in the presence of blockers of fast synaptic transmission (Hayar et al., 2004a,b). These results indicate that fast synaptic transmission is not required for correlated bursting, but that it influences the timing of burst occurrence. Indeed, ET cell spike bursts can be precisely timed by sensory input. For example, ET cells with different intrinsic bursting frequencies are readily entrained by repetitive olfactory nerve $(\mathrm{ON})$ input delivered at frequencies in the theta range $(5-10 \mathrm{~Hz})$ (Hayar et al., 2004a). Pairs of ET cells of the same glomerulus have highly correlated spontaneous activity (Hayar et al., 2004b). The mechanisms underly-

\footnotetext{
Received March 1, 2005; revised July 27, 2005; accepted July 27, 2005.

This work was supported by National Institutes of Health Grants DC06356, DC05676, DC07123, and DC03195. We thank Drs. Sergei Karnup and Dongxia Jiang for developing and reconstructing biocytin-filled cells.

Correspondence should be addressed to Dr. Abdallah Hayar, Department of Anatomy and Neurobiology, University of Tennessee Health Science Center, 855 Monroe Avenue, Suite 515, Memphis, TN 38163. E-mail: ahayar@utmem.edu.

DOI:10.1523/JNEUROSCI.2374-05.2005

Copyright $\odot 2005$ Society for Neuroscience $\quad$ 0270-6474/05/258197-12\$15.00/0
}

ing ET cell synchrony are unknown. Because synaptic input can alter ET cell burst timing, synaptic activity may also play a role in synchronizing bursts among ET cells.

The roles of ionotropic glutamatergic and GABAergic synaptic input in synchronizing ET cell discharge are unknown. Olfactory nerve terminals may initiate synchronized activity within a single glomerulus by providing a common excitatory input to ET cells, whose dendrites extensively ramify throughout that glomerulus (Hayar et al., 2004a). Periglomerular (PG) cells receive and integrate barrages of direct excitatory inputs from several ET cells (Hayar et al., 2004b). PG cells, which greatly outnumber ET cells, are therefore well positioned to provide synchronous feedback inhibition, which could influence the timing and synchrony of ET cell spike bursts. However, in contrast to the granule-mitral cell dendrodendritic synapse, which has been extensively studied in the past few years (for review, see Schoppa and Urban, 2003), little is known about the PG-ET cell dendrodendritic synapses.

In this study, we investigated potential mechanisms involved in synchronizing ET cell activity. For this purpose, we have addressed the following questions. (1) Do ET cells receive a correlated pattern of spontaneous excitatory and inhibitory synaptic currents? (2) Do they respond in a similar way to olfactory nerve and mitral/tufted cell stimulation? (3) Are excitatory and inhibitory inputs correlated in ET cells of the same glomerulus? (4) Is glomerular affiliation important for detecting correlated activity? (5) Are there synaptic or gap junction connections among ET cells of the same glomerulus? Our results indicate that ET cell 
synchrony is limited to cells of the same glomerulus. This indicates that ET cell synchrony is attributable to intraglomerular mechanisms. The results further show that both synaptic and gap junction coupling coordinate ET cell bursting activity.

\section{Materials and Methods}

Slice preparation. Sprague Dawley rats (21-29 d old), of either sex, were decapitated in accordance with Institutional Animal Care and Use Committee and National Institutes of Health guidelines. The olfactory bulbs were removed and immersed in sucrose-artificial CSF (aCSF) equilibrated with $95 \% \mathrm{O}_{2}-5 \% \mathrm{CO}_{2}$, pH 7.38. The sucrose-aCSF had the following composition (in mM): $26 \mathrm{NaHCO}_{3}, 1 \mathrm{NaH}_{2} \mathrm{PO}_{4}, 2 \mathrm{KCl}, 7 \mathrm{MgCl}_{2}$, $0.5 \mathrm{CaCl}_{2}, 20$ glucose, 0.4 ascorbic acid, 2 sodium pyruvate, and 234 sucrose. Horizontal slices ( $400 \mu \mathrm{m}$ thick) were cut with a Vibratome 3000 (Vibratome, St. Louis, MO). After a period of recovery at $30^{\circ} \mathrm{C}$ for $15 \mathrm{~min}$, slices were then incubated at room temperature $\left(22^{\circ} \mathrm{C}\right)$ in aCSF equilibrated with $95 \% \mathrm{O}_{2}-5 \% \mathrm{CO}_{2}$ (composition in mM: $124 \mathrm{NaCl}, 26$ $\mathrm{NaHCO}_{3}, 3 \mathrm{KCl}, 2 \mathrm{MgCl}_{2}, 2 \mathrm{CaCl}_{2}, 0.4$ ascorbic acid, 2 sodium pyruvate, and 20 glucose), until used. For recording, a single slice was placed in a recording chamber and continuously perfused at the rate of $1.5 \mathrm{ml} / \mathrm{min}$ with normal aCSF equilibrated with $95 \% \mathrm{O}_{2}-5 \% \mathrm{CO}_{2}$. All recordings were performed at $30^{\circ} \mathrm{C}$. Neurons were visualized using an upright microscope (BX50WI; Olympus Optical, Tokyo, Japan) equipped for epifluorescence and near-infrared differential interference contrast optics.

Recording solutions and cell identification. Patch pipettes were pulled from borosilicate glass capillaries with an inner filament $(1.5 \mathrm{~mm}$ outer diameter; Clark, Kent, UK) on a pipette puller (P-97; Sutter Instruments, Novato, CA). All ET cells were first identified by their relatively large soma compared with other juxtaglomerular cells and by their characteristic spontaneous rhythmic spike bursting pattern (see below) recorded extracellularly before recording in whole-cell voltage-clamp mode. All recorded neurons were morphologically confirmed to be ET cells using intracellular labeling with Lucifer yellow for on-line visualization and biocytin for post hoc morphological reconstruction and analysis. ET cells have an extensive intraglomerular ramification, and their apical tufts occupy, on average, $80 \%$ of the area of a glomerulus in two-dimensional reconstruction (Hayar et al., 2004a). Extracellular recordings were obtained using patch pipettes filled with aCSF. For intracellular recordings of EPSCs and IPSCs, electrodes were filled with a solution of the following composition (in mM): 125 cesium methanesulfonate $\mathrm{CsMeSO}_{3}, 1$ $\mathrm{NaCl}, 10$ phosphocreatine ditris salt, $4 \mathrm{MgATP}, 0.3 \mathrm{GTP}, 0.5$ EGTA, 10 HEPES, and 10 QX-314 [2(triethylamino)- $N$-(2,6-dimethylphenyl) acetamine], pH 7.3 with $\mathrm{NaOH}$ (osmolarity, 290 Osm). Although the recording pipette contained a low chloride concentration $(1 \mathrm{~mm}$, the theoretical reversal potential for chloride ions was approximately -120 $\mathrm{mV}$ ), detectable outward currents (i.e., IPSCs) were only observed at a holding potential $(\mathrm{HP})$ positive to $-50 \mathrm{mV}$. It is possible that the reversal potential of $\mathrm{GABA}_{\mathrm{A}}$ receptors was rendered positive if these receptors were partially permeable to methanesulfonate anions $(120 \mathrm{~mm}$ in the pipette) or possibly to highly efficient chloride pumps. However, this possibility was not investigated further. For intracellular recording of spiking activity, electrodes were filled with a solution of the following composition (in mM): $134 \mathrm{~K}$-gluconate, $4 \mathrm{NaCl}, 4 \mathrm{MgCl}_{2}, 10$ HEPES, 0.2 EGTA, $3 \mathrm{Mg}_{2} \mathrm{ATP}$, and $0.3 \mathrm{Na}_{2} \mathrm{GTP}$, pH 7.3 with $\mathrm{KOH}$ (osmolarity, 290 Osm). In all experiments, $0.02 \%$ Lucifer yellow and $0.2 \%$ biocytin (Molecular Probes, Eugene, OR) were added to the intracellular solution for in situ and post hoc labeling, respectively. The pipette resistance was 5-8 $\mathrm{M} \Omega$. Photos of Lucifer yellow-labeled cells were obtained using a 5 megapixel digital camera (Coolpix 5700; Nikon, Tokyo, Japan) connected to the microscope eyepiece via an adapter (MM99-5700; Martin Microscope, Easley, SC). Dual recordings were made using two Axopatch-200B amplifiers (Axon Instruments, Union City, CA). The junction potential was $9-10 \mathrm{mV}$, and all reported voltage measurements were uncorrected for these potentials. Only neurons with access resistance $<30 \mathrm{M} \Omega$ were included in this study. No series resistance compensation was performed. Electrical stimulation (Grass S8800 stimulator; Astro-Med, West Warwick, RI) was performed using two stainless steel wires (50 $\mu \mathrm{m}$ in diameter; A-M Systems, Everett, WA), insulated except at their tips positioned in the olfactory nerve layer. Isolated, constantcurrent stimulus pulses of 10-200 $\mu \mathrm{A}$ and $200 \mu$ s duration were applied. The stimulating electrode was always placed in the olfactory nerve layer immediately adjacent to the glomerulus at which recordings were made. Drugs and solutions of different ionic content were applied to the slice by switching the perfusion with a three-way electronic valve system. Tetrodotoxin (TTX), QX-314, gabazine [SR95531 (2-(3-carboxypropyl)-3amino-6-(4-methoxyphenyl)pyridazinium bromide)], 6-cyano-7-nitroquinoxaline-2,3-dione (CNQX), and ( \pm )-2-amino-5-phosphopentanoic acid (APV) were purchased from Research Biochemicals (Natick, MA) Biocytin-filled cells were developed as described previously (Karnup and Stelzer, 1999). Briefly, fixed slices were embedded in 10\% gelatin and sectioned at $80 \mu \mathrm{m}$ thickness using a vibratome. The sections were reacted with $1 \% \mathrm{H}_{2} \mathrm{O}_{2}, 0.5 \%$ Triton X-100, ABC complex, and Ni-DAB chromogen. After dehydration, the sections were mounted in distrene plasticizer xylene. Two-dimensional reconstructions of filled neurons were made with Neurolucida software (MicroBrightField, Colchester, VT).

Data analysis. Analog signals were low-pass filtered at $2 \mathrm{kHz}$ (Axopatch 200B) and digitized at $5 \mathrm{kHz}$ using a Digidata-1322A interface and pClamp9 software (Axon Instruments). The detection of events (extracellularly recorded spikes and intracellularly recorded EPSCs and IPSCs) were performed off-line using Mini Analysis program (Synaptosoft, Decatur, GA). Consecutive epochs of data (e.g., $12 \mathrm{~ms}$ ) were searched for a peak current, and the average baseline current was calculated for an interval (e.g., between 3 and $4 \mathrm{~ms}$ ) before the peak. The event amplitude was calculated by subtracting the average baseline current from the peak current, and the event was rejected if the amplitude did not exceed a given threshold (e.g., $5 \mathrm{pA}$ ). The times of occurrence of events were imported into Origin 7.0 (Microcal Software, Northampton, MA) for additional analysis using algorithms written in LabTalk.

An EPSC in one cell was considered to be synchronous with an EPSC in a second cell if the onset times of the two EPSCs were $<500 \mu$ s apart (equivalent to less than three sampling points because data were acquired at $5 \mathrm{kHz}$ ). This criterion of synchrony is based on the assumption that two synchronous EPSCs result from a single spike invasion of a presynaptic terminal providing a common input to the two simultaneously recorded cells. The time interval of $500 \mu$ s takes into account the possibility that a small synaptic jitter might exist attributable to a slight variability in the latency of the neurotransmitter release process.

Event train cross-correlograms (bin, 1 or $2 \mathrm{~ms}$ ) were obtained using data acquired during 5-10 min in each recording condition. To compare the degree of correlation in different pairs or in the same pair in different conditions, cross-correlograms were normalized to the frequency of events of both cells, the bin width, and the sampling period (MannMetzer and Yarom, 1999). Thus, the correlation coefficients $(C)$ indicate how frequently one cell exhibits synchronous events with another cell compared with chance ( $C=1$ for event trains). Cross-correlograms were normalized by dividing the counts in each bin by a coefficient $(N)$, which is the number of events expected by chance during one bin: $N=F 1 \times$ $F 2 \times P \times B$, where $F 1$ and $F 2$ are the mean frequencies of events (in Hertz) in the first and second cell, respectively, $P$ is the sampling period (seconds) used for analysis, and $B$ is the duration (seconds) of one bin. For autocorrelograms, $F 1$ equals $F 2$. A $C$ of $>1+3 \times$ SD (i.e., confidence limit $>99.73 \%$ ) indicates significant positive correlation, where SD is the standard deviation of the cross-correlation of the spike trains at time lags between 1.5 and $2 \mathrm{~s}$ (shift predictor method) (Gerstein and Perkel, 1972). This method is based on the idea that most neuronal interactions occur on a short timescale and on the assumption that the time shift (1.5-2 s) is much larger than the delay usually involved in neuronal interactions (Aertsen et al., 1989).

Membrane current cross-correlograms were constructed from $50 \mathrm{~s}$ simultaneous recording samples from each pair of cells. Current traces (digitized at $5 \mathrm{kHz}$ ) were offset by their mean and then reduced by group averaging to one point per $2 \mathrm{~ms}$. Cross-correlograms of the current traces were constructed and normalized by the square root of the product of the autocorrelation values of the two traces at zero lag time. The coefficients of correlation (theoretical maximum of 1 for waveforms) measure the degree to which changes in membrane current of each cell were correlated. The coefficient of correlation of the membrane current 

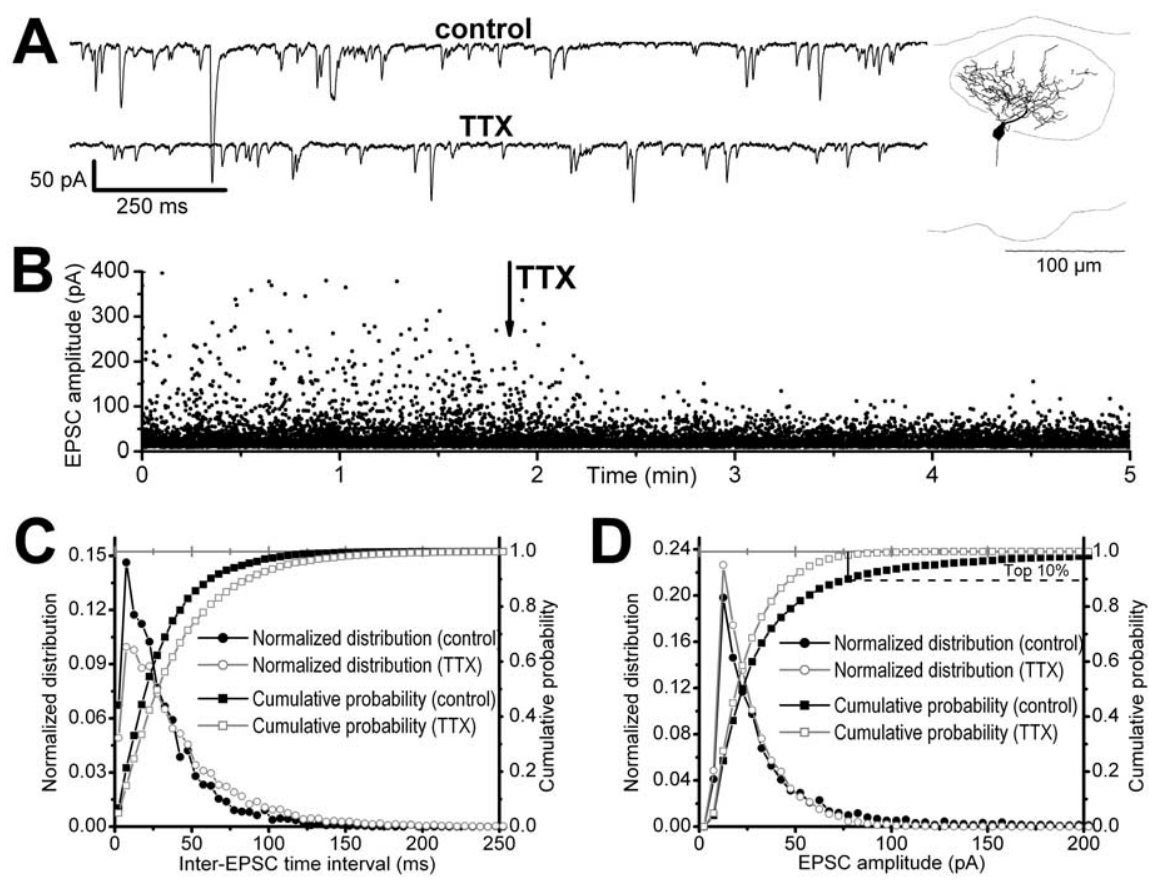

Figure 1. TTX sensitivity of spontaneous EPSCs in ET cells. $\boldsymbol{A}$, Voltage-clamp recordings (HP of $-60 \mathrm{mV}$ ) of an ET cell, showing the effect of TTX (1 $\mu \mathrm{m})$ on spontaneous EPSCs. The inset at right shows a Neurolucida drawing of the ET cell. Note the highly branched tufted dendrites that ramify throughout a large portion of a single glomerulus (closed line). The thin lines above and below the cell indicate boundaries of the glomerular layer with the olfactory nerve layer and external plexiform layer, respectively. $\boldsymbol{B}$, Scatter plot of the amplitude of EPSCS of the ET cell shown in $\boldsymbol{A}$. TTX preferentially eliminated relatively large amplitude EPSCs. $\boldsymbol{C}, \boldsymbol{D}$, Histograms of inter-EPSC time interval and amplitude distributions, respectively, for the ET cell shown in $\boldsymbol{A}$. Also shown are the cumulative probability distributions, which indicate significant difference between control and TTX ( $p<0.0001, \mathrm{~K}-\mathrm{S}$ test). The largest $10 \%$ of the EPSCS (dashed horizontal line in $\boldsymbol{D}$ ) were eliminated by TTX.

$[C($ current $)]$ values were considered significant if they were at least three times higher than the SD of the $[C$ (current) $]$ values of the time-shifted (5 s) membrane current (confidence limit $>99.73 \%$ ).

Custom-designed computer algorithms were used off-line to evaluate the pattern of bursting of events (e.g., spikes and IPSCs) throughout the experiments by measuring the following parameters: event frequency, bursting frequency (defined as the number of bursts of events per second), events/burst, intraburst frequency (defined as the frequency of events within a burst), and burst duration (defined as the time interval between the first and the last event in a burst). A spike burst was defined, as in previous quantitative studies of ET cell spontaneous firing (Hayar et al., 2004a) as two or more consecutive spikes that had interspike time intervals of $<75 \mathrm{~ms}$ (i.e., an interspike time interval of $>75 \mathrm{~ms}$ was considered to signal the beginning of another burst); on average, ET cell bursts consist of 5.4 spikes (range of 2-12 spikes) (Hayar et al., 2004a). An IPSC burst was defined as a series of four or more consecutive IPSCs occurring at $<50 \mathrm{~ms}$ intervals (i.e., $>20 \mathrm{~Hz}$ ). A moving average of each parameter (over $1 \mathrm{~min}$ ) was also computed to dampen fast variations and evaluate the mean of each parameter in different conditions.

Data, expressed as mean \pm SEM, were statistically analyzed using paired $t$ test (Origin 7.0 software) unless otherwise stated. Difference in distributions was analyzed using Kolmogorov-Smirnov test (K-S test) (Clampfit 9.2 software).

\section{Results}

ET cells of the same glomerulus exhibit synchronous bursting activity. In contrast, no ET cells of different glomeruli are synchronous, although a small proportion exhibit correlated activity at a very long time lag (mean of $115 \mathrm{~ms}$ ) (Hayar et al., 2004b). This indicates that the mechanisms underlying ET cell synchrony are intraglomerular in origin. The following experiments inves- tigate whether these intraglomerular mechanisms involve synaptic and gap junction interactions.

Spontaneous synaptic input to ET cells The temporal pattern and magnitude of synaptic inputs is important in determining their effectiveness in timing spike occurrence (Singer and Gray, 1995). Spike bursting in ET cells is triggered, in part, by infrequent but relatively large EPSPs (Hayar et al., 2004a) (see Fig. 6). Such large EPSPs may result from network activity, but the proportion of spike-driven EPSCs in ET cells is not known. To investigate this, we tested the sensitivity of the spontaneous EPSCs in ET cells to TTX $(1 \mu \mathrm{M})$. Most of the spontaneous EPSCs $(79 \pm 2 \%)$ in ET cells persisted in TTX (control, $22 \pm$ $4 \mathrm{~Hz}$ vs TTX, $17 \pm 3 \mathrm{~Hz} ; n=8 ; p<0.001)$ (Fig. $1 A$ ), indicating that the majority of excitatory synaptic inputs to ET cells are action potential-independent events or miniature EPSCs. The relatively high proportion of miniature EPSCs may reflect the large number of olfactory axons $(\sim 25,000)$ converging onto few ET cells per single glomerulus (Shipley et al., 1996).

The mean reduction in EPSC frequency by TTX was $4.8 \pm 1.0 \mathrm{EPSCs} / \mathrm{s}(n=8$; range, 1.3-8 EPSCs/s), which corresponded to a significant increase in interEPSC time intervals ( $p<0.0001, \mathrm{~K}-\mathrm{S}$ test $)$ (Fig. 1C). The average mean amplitude of EPSCs was significantly reduced by TTX (control, $38 \pm 6$ pA; TTX, $27 \pm 4$ pA; $n=8 ; p<$ 0.05). Moreover, EPSCs that were eliminated by TTX were relatively large, as shown by the amplitude distribution histograms $(p<0.0001, \mathrm{~K}-\mathrm{S}$ test) (Fig. $1 B, D)$. These results indicate that the larger the EPSCs, the more likely they result from action potentials. Although TTX-sensitive EPSCs constitute only 20\% of the spontaneous EPSCs, they are more likely to synchronize spike bursting in ET cells because of their relatively larger amplitude (see below).

Previous studies (Pinching and Powell, 1971a,b; Ribak et al., 1977; Kosaka et al., 1985) indicate that PG cells, many of which are GABAergic, form reciprocal dendrodendritic synapses with mitral/tufted cells and ET cells. Because PG cells receive barrages of monosynaptic EPSPs from synchronously bursting ET cells (Hayar et al., 2004b), they could provide coordinated inhibitory feedback, which may synchronize the activity of ET cells. We tested this hypothesis by determining whether the spontaneous IPSCs in ET cells, which indirectly reflect the firing activity of PG cells, have a bursting pattern and, if so, whether such activity involves NMDA receptors as in granule-to-mitral dendrodendritic synapses (for review, see Schoppa and Urban, 2003). We recorded IPSCs in ET cells at an $\mathrm{HP}$ of $0 \mathrm{mV}$ (near the reversal potential of AMPA-mediated EPSCs) (Fig. $2 A$ ). The frequency of spontaneous IPSCs was reduced by $26 \pm 3 \%(p<0.001)$ by the NMDA receptor antagonist APV $(50 \mu \mathrm{M})$ and was further reduced by $37 \pm 4 \%(p<0.001)$ by additional application of CNQX $(10 \mu \mathrm{M}$; control, $7.2 \pm 0.8 \mathrm{IPSCs} / \mathrm{s}$; APV, $5.5 \pm 0.7$ IPSCs/s; APV plus CNQX, $2.8 \pm 0.5$ IPSCs/s; $n=8)($ Fig. $2 A, B)$. 
Additional application of gabazine (10 $\mu \mathrm{M} ; n=8$ ) blocked the remaining IPSCs. These results suggest that the GABA release from PG cells depends on fast glutamatergic synaptic transmission.

To characterize the pattern of spontaneous IPSCs, we defined an IPSC burst as a series of four or more consecutive IPSCs occurring at $<50 \mathrm{~ms}$ intervals (i.e., $>20$ $\mathrm{Hz}$; see Materials and Methods). The frequency of such spontaneous IPSC bursts, $0.43 \pm 0.05$ bursts/s, was significantly reduced by APV to $0.23 \pm 0.04$ bursts/s ( $n=$ $7 ; p<0.01$ ) (Fig. $2 A, B$ ); additional application of CNQX virtually eliminated bursts $(0.006 \pm 0.004$ bursts/s; $p<0.01)$. The mean intraburst frequency of IPSCs was not changed by APV (control, $47 \pm 2$ IPSCs/s; APV, $46 \pm 2$ IPSCs/s; $p=0.29$ ), whereas the mean number of IPSCs per burst was slightly reduced (control, $5.6 \pm$ 0.3 IPSCs per burst; APV, $5.1 \pm 0.2$ IPSCs per burst; $p<0.01)$. Therefore, blockade of NMDA receptors reduces IPSC burst frequency and the number of IPSCs/burst without changing intraburst IPSC frequency. In contrast, blockade of nonNMDA receptors eliminate bursts of IPSCs. This indicates that the activity of inhibitory cells presynaptic to ET cells depends on excitatory fast synaptic transmission mediated by non-NMDA receptors and, to a lesser extent, by NMDA receptors.

Autocorrelograms of the IPSCs occurring during 5 min were analyzed to identify the dominant IPSC frequency (Perkel et al., 1967; Hayar et al., 2004a,b). All autocorrelograms exhibited a significant peak $[C($ IPSCs $)=2.4 \pm 0.3$; range, $1.9-3.8 ; n=6$; confidence limit $>99.73 \%$ ] (Fig. $2 C$ ) at a lag time of $18 \pm 1 \mathrm{~ms}$ (range, 14-21 ms), which corresponds to a dominant intraburst IPSC frequency of $\sim 55 \mathrm{~Hz}$. The IPSC bursts persisted in APV but were abolished by additional application of CNQX (Fig. 2D). Together, these findings are consistent with the hypothesis that the ensemble of PG cells provides a bursting inhibitory feedback to ET cells.

\section{Similarity of spontaneous and olfactory nerve-evoked EPSC-IPSC sequences}

The relatively large EPSCs and the bursts of IPSCs in ET cells may reflect coordinated firing activity of excitatory and inhibitory presynaptic neurons, respectively. This hypothesis was tested by recording EPSCs and IPSCs simultaneously, at a holding potential intermediate to the reversal potential of $\mathrm{GABA}_{\mathrm{A}}$ receptors and ionotropic glutamate receptors (Yang et al., 2001). An HP of -30 $\mathrm{mV}$ was optimal to record IPSCs and EPSCs simultaneously (Fig. $3 B$ ). Bursts of spontaneous IPSCs in all 15 ET cells tested were often preceded by unitary, relatively large amplitude EPSCs. EPSCs larger than 20 pA were followed by IPSCs $57 \pm 6 \%$ of the time ( $n=6$ cells). EPSC-triggered averaging was used to quantify the temporal EPSC-IPSC relationship. For this analysis, averages of 100-200 traces triggered on EPSCs of 20-25 pA or larger were used to detect the largest 20-30\% of spontaneous EPSCs (Fig. $3 C, E)$. There was a significant positive correlation between the amplitude of EPSC and the peak amplitude of the burst of IPSCs. As shown in Figure 3D, the larger the EPSC amplitude, the larger was the peak amplitude of IPSC burst that followed the EPSC. The average of EPSC-triggered traces revealed a significant outward current representing a burst of IPSCs after the large EPSCs in all cells (Fig. $3 C, E$ ). The envelope of IPSCs reached a peak at $\sim 67 \mathrm{~ms}$, after the peak of the EPSC (Fig. 3E). The average IPSC burst decayed with a time constant $(\tau)$ of $68 \mathrm{~ms}$, which is 10-fold longer than the average decay time constant of the preceding EPSC $(\tau=6.8 \mathrm{~ms})$. The temporal association between large EPSCs and IPSC bursts suggests that the EPSCs and the following IPSC burst may play a role in triggering and terminating the spike bursts, respectively. Alternatively, because the IPSCs are generated in the dendrites of ET cells, they may play a role in limiting transmitter release from, or shunting ON inputs to, ET cell dendrites.

The relatively large spontaneous EPSCs preceding IPSC bursts may derive, in part, from action potentials in presynaptic olfactory nerve terminals. To test this, we stimulated the olfactory nerve layer to see whether this evoked an EPSC-IPSC sequence similar to spontaneous sequences. In all ET cells tested $(n=6)$, low-intensity stimulation (35-50 $\mu \mathrm{A})$ of the olfactory nerve layer produced a constant latency single EPSC, followed by a burst of IPSCs at an HP of $-30 \mathrm{mV}$ (Fig. $3 F$ ). At an $\mathrm{HP}$ of $0 \mathrm{mV}$ (near the reversal potential of ionotropic glutamate receptors), olfactory nerve stimulation produced an IPSC burst with a mean latency to the first IPSC of $8.8 \pm 1.6 \mathrm{~ms}$, and a mean SD ("synaptic jitter") of $2.6 \pm 0.7 \mathrm{~ms}$. This relatively longer and more variable latency to evoked IPSCs compared with that of evoked EPSCs (mean la- 


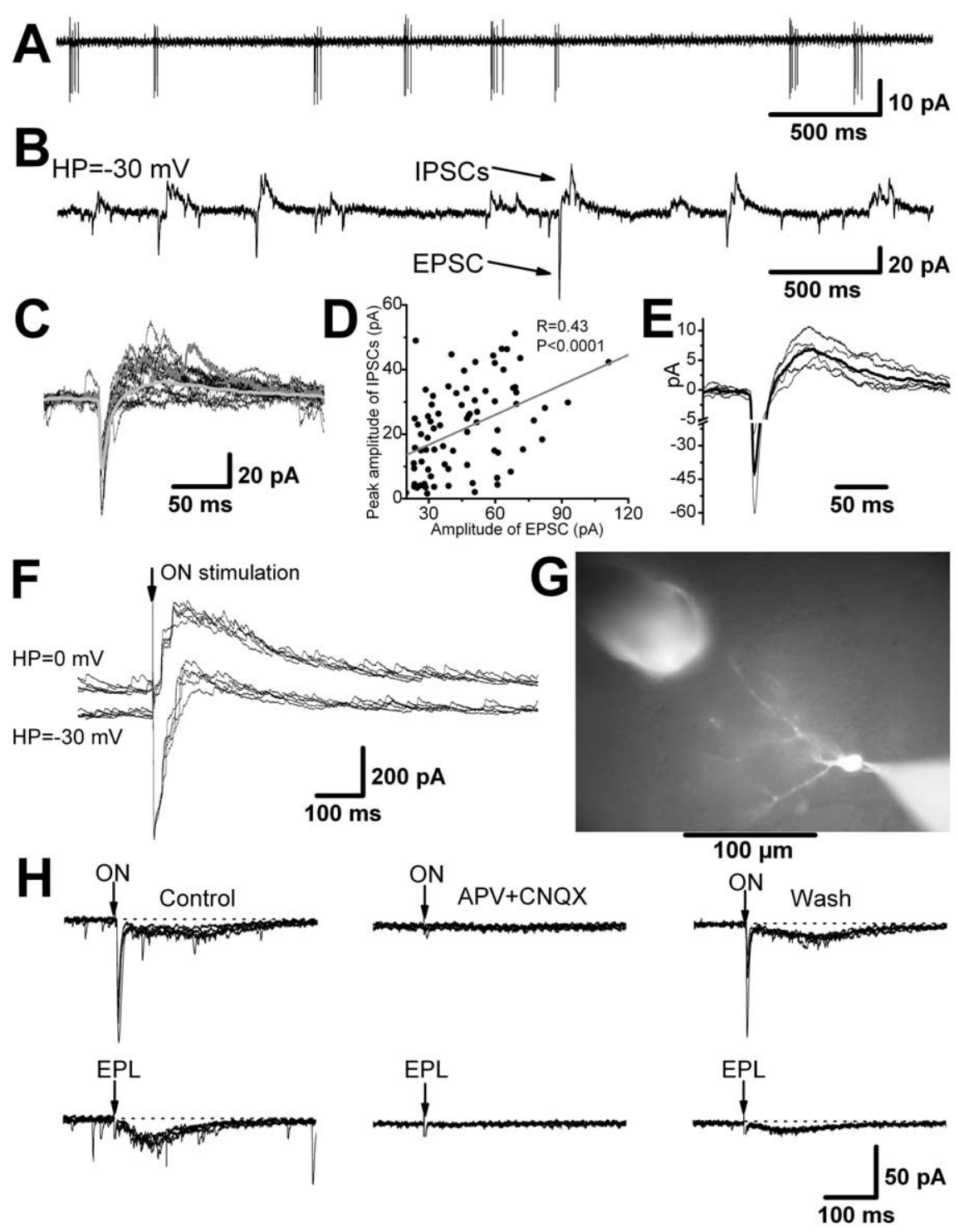

Figure 3. Pattern of spontaneous and evoked EPSCs and IPSCS. $\boldsymbol{A}-\boldsymbol{D}, \boldsymbol{F}$, and $\boldsymbol{G}$ were obtained from the same cell. $\boldsymbol{A}$, An ET cell was first recorded extracellularly, and then (in $\boldsymbol{B}$ ) the same cell was recorded intracellularly in voltage clamp ( $\mathrm{HP}$ of $-30 \mathrm{mV}$ ) using a patch pipette containing $\mathrm{CSMeSO}_{3}$ and QX-314. The cell displayed relatively large amplitude EPSCS (downward deflections), followed by bursts of IPSCS (upward deflections). C, Superimposed traces $(n=20)$ were triggered on relatively large spontaneous EPSCS. Most of the EPSCS were followed by a cluster of IPSCS (dark gray line is a typical example). The average (light gray line) of 150 such traces indicates that a significant outward current followed the EPSCS. D, Scatter plot of the peak amplitude of IPSCS versus the amplitude of the preceding EPSC. The linear curve fit (gray line) indicates significant positive correlation. $\boldsymbol{E}$, Averaged trace (thicker line) of the mean of 100-200 EPSC-IPSC traces as obtained in C from five ET cells. The average trace indicates that the outward current of the IPSCs peaked at $63 \mathrm{~ms}$ from the onset of the EPSC and decayed with a time constant of $68 \mathrm{~ms} . \boldsymbol{F}$, Olfactory nerve layer stimulation evoked the same sequence of currents; short-latency EPSC, followed by a burst of IPSCS. At the holding potential of $0 \mathrm{mV}$ (near the reversal potential of excitatory ionotropic receptors), only the IPSCs were observed. $\mathbf{G}$, Photograph of the ET cell filled with the Lucifer yellow during recording (note stimulation electrode at top left). $\boldsymbol{H}, \mathbf{O N}$ stimulation $(55 \mu \mathrm{A})$ evoked a fast EPSCs followed by a slow EPSCs, whereas EPL $(550 \mu \mathrm{A})$ stimulation evoked only slow EPSCs. All evoked EPSCs were reversibly blocked by APV and CNQX. Five superimposed traces are shown in each stimulation condition. Stimulation artifacts were truncated for clarity.

tency of $2.1 \pm 0.05 \mathrm{~ms}$; SD of $87 \pm 9 \mu \mathrm{s}$ ) (Hayar et al., 2004a) indicates that olfactory nerve axons inhibit ET cells indirectly via GABAergic interneurons.

To explore additional potential sources of fast EPSCs, we compared ET cell responses to stimulation of the olfactory nerve versus stimulation of the external plexiform layer (EPL) (Fig. $3 H$ ) (HP of $-60 \mathrm{mV}$ ). In 15 cells tested, olfactory nerve stimulation produced a short-latency EPSC; in 11 of the 15 cells, the fast EPSC was followed by a slow EPSC (peak occurs at 100-150 ms from stimulation). Next, in the same cells, the EPL was stimulated to antidromically activate ET cells and mitral/tufted cell apical dendrites. EPL stimulation never evoked fast EPSCs. Instead, it produced only a delayed slow EPSC in 10 of 15 ET cells. Coapplication of CNQX and APV reversibly blocked olfactory nerveevoked fast and slow, and EPL-evoked slow, inward currents (tested in the same cells, $n=5$ ). These results are consistent with the hypothesis that spontaneous, fast unitary EPSCs that are followed by an IPSC burst or a slow EPSC may be initiated by action potentials in olfactory nerve terminals. It is possible that fast EPSCs may be generated, in part, by glomerular layer interneurons such as short axon cells (Aungst et al., 2003), but, because these cells have low spontaneous activity, this seems unlikely.

\section{Coincident excitatory synaptic input to different ET cells}

ET cells continue to burst synchronously in the presence of fast synaptic blockers (Hayar et al., 2004b). It is unknown whether excitatory synaptic input could play a role in coordinating ET cell activity. This was investigated by determining whether ET cells of the same glomerulus exhibit synchronous spontaneous EPSCs. Extracellular recordings were made from 10 ET-ET cell pairs with correlated bursting assessed on-line (Fig. 4A) and confirmed by spike train cross-correlations $[C($ spikes $)=4.3 \pm 1.3$; range, $1.4-11.8$; confidence limit >99.73\%] (Fig. 4C). Next, patch pipettes (containing cesium and QX-314 to enhance EPSC detection) were used to record from the same pairs at an $\mathrm{HP}$ of $-60 \mathrm{mV}$ (Fig. $4 \mathrm{~B}$ ) to determine whether they had synchronous EPSCs (defined as EPSCs with onset times $<500 \mu \mathrm{s}$ apart; see Materials and Methods). Crosscorrelation analysis was performed to determine whether the synchrony of EPSCs was significant (see Materials and Methods). In six of six pairs, the crosscorrelograms of the EPSC trains (binned at $1 \mathrm{~ms}$ ) exhibited a significant peak $[C$ (EPSCs) $=2.76 \pm 0.35 ;$ range, 1.35-3.57 at time lag 0] (Fig. 4E); this cross-correlation was significantly higher than expected by chance $[C($ chance $)=1$; confidence limit $>99.73 \%$ ). Intracellular labeling confirmed that all pairs were affiliated with the same glomerulus (Fig. $4 H$ ). Thus, ET cells of the same glomerulus receive synchronous spontaneous EPSCs.

The frequency of synchronous EPSCs was $0.38 \pm 0.14 \mathrm{EPSC} / \mathrm{s}$ ( $n=6$ pairs, range $0.11-1.04$ EPSCs/s) (Fig. $4 B$ ). The synchronous EPSP/Cs in all six ET cell pairs ( $n=12$ cells) had a larger mean amplitude (49.5 $\pm 6.7 \mathrm{pA}$; range, $18.5-91.7 \mathrm{pA})$ than asyn- 
chronous EPSP/Cs (18.2 $\pm 1.2 \mathrm{pA}$; range, 10.9-26.1 pA; $p<0.001$ ) (Fig. $4 F$ ). This result suggests that synchronous EPSCs might be driven by action potentials in presynaptic terminals because large EPSCs were blocked by TTX, as shown above (Fig. 1). Moreover, the amplitudes of synchronous EPSCs were correlated in all pairs, i.e., synchronous EPSCs tend to have comparable amplitudes (mean coefficient of linear regression fit, $r=0.43 \pm 0.06$; range, $0.27-0.64 ; p<0.0001$ in four pairs and $p<0.01$ in two pairs) (Fig. 4G). These observations indicate that synchronous fast EPSCs are generated by a common mechanism. Therefore, ET cells of the same glomerulus are excited simultaneously at similar intensity by a common input and may therefore respond with synchronous spike bursts of similar magnitude.

In voltage-clamp recordings, some ET cell pairs exhibited slow $(>50 \mathrm{~ms}$ duration) inward currents that appeared to be correlated and could potentially provide an additional mechanism of synchrony. Because these slow currents had variable kinetics, it was not possible to detect them using event detection methods as for fast EPSCs above. We therefore cross-correlated the membrane current waveforms of the 10 ET cell pairs. The coefficient of correlation for membrane current (theoretical maximum of 1) indicates the degree to which changes in membrane current of cell pairs were correlated (thus taking into account the amplitude of synaptic currents). The membrane current cross-correlograms for all 10 ET cell pairs exhibited a significant peak coefficient of correlation [C(current $)=0.49 \pm 0.05$; range, $0.26-0.72$; confidence limit $>99.73 \%$ ] at zero lag time, thus providing additional evidence for EPSC synchrony. All cross-correlograms exhibited a narrow window of significant correlation ( $30 \pm 3 \mathrm{~ms}$; range, $18-40 \mathrm{~ms}$ ), corresponding to the occurrence of fast synchronous EPSCs. In 8 of the 10 pairs, the narrow correlation was superimposed on a broader correlation (721 $\pm 222 \mathrm{~ms}$; range, 232-2000 ms) (Fig. $4 D)$, showing that the slow inward currents in these eight pairs were also correlated. Fast and slow spontaneous EPSCs were similar to evoked ones (see above) in that they were blocked by CNQX and APV ( $n=8$ cells; data not shown), indicating that they were attributable to glutamatergic synapses.

Could synchronous EPSCs in ET cells trigger synchronous bursting? To investigate this question, dual current-clamp recordings from five ET cell pairs were performed (using potassium gluconate-filled electrodes). All five pairs exhibited synchronous fast and slow EPSPs (average frequency, $1.0 \pm 0.2 \mathrm{~Hz} ; n=5$; range, $0.13-2.1 \mathrm{~Hz}$ ). The synchronous fast EPSPs had relatively large amplitudes and frequently lead to burst firing in one of the cells or both at resting potential (Fig. $5 A 1, A 2, B$ ). Synchronous EPSP/Cs were completely abolished in TTX ( $1 \mu \mathrm{M} ; n=3)$ (Fig. $5 A 3, A 4)$, indicating that they are attributable to action potentialdependent network activity. Thus, ET cells of the same glomeru- lus receive common excitatory inputs that can synchronize their bursting.

\section{Coincident inhibitory synaptic input to ET cells}

Because spontaneous and olfactory nerve-evoked bursts of IPSCs in ET cells are often preceded by relatively large amplitude EPSCs, which are synchronous in ET cells of the same glomerulus, we asked whether IPSCs in ET cells of the same glomerulus are correlated. IPSCs ( $\mathrm{HP}$ of $0 \mathrm{mV}$ ) were recorded from the eight ET-ET cell pairs used in the preceding EPSC analysis. All eight pairs exhibited correlated bursts of IPSCs (Fig. 6A). The crosscorrelograms of the membrane currents for all eight pairs exhibited a significant peak $[C$ (current $)=0.54 \pm 0.08$; range, $0.18-$ 0.79 ; confidence limit $>99.73 \%$ ) (Fig. $6 B$ ) at a mean lag time of $5 \pm 4 \mathrm{~ms}$ (range, $0-34 \mathrm{~ms}$ ). Because the IPSCs occurred mostly in bursts, the time window of significant correlation was relatively long (401 $\pm 48 \mathrm{~ms}$; range, $150-600 \mathrm{~ms}$ ). To determine whether individual IPSCs among ET cell are synchronous, we crosscorrelated IPSCs for four ET cell pairs. All four pairs exhibited both a narrow peak of correlation $[C($ IPSCs $)=5.3 \pm 1.2$; range, $3.4-8.5$; confidence limit $>99.73 \%$ ) at lag time $0 \mathrm{~ms}$ with a narrow time window (1-2 ms width), indicating synchrony of individual IPSCs; this sharp peak was superimposed on a broader correlation of $\sim 422 \mathrm{~ms}$ (Fig. $6 \mathrm{C}$ ), which represented the majority 


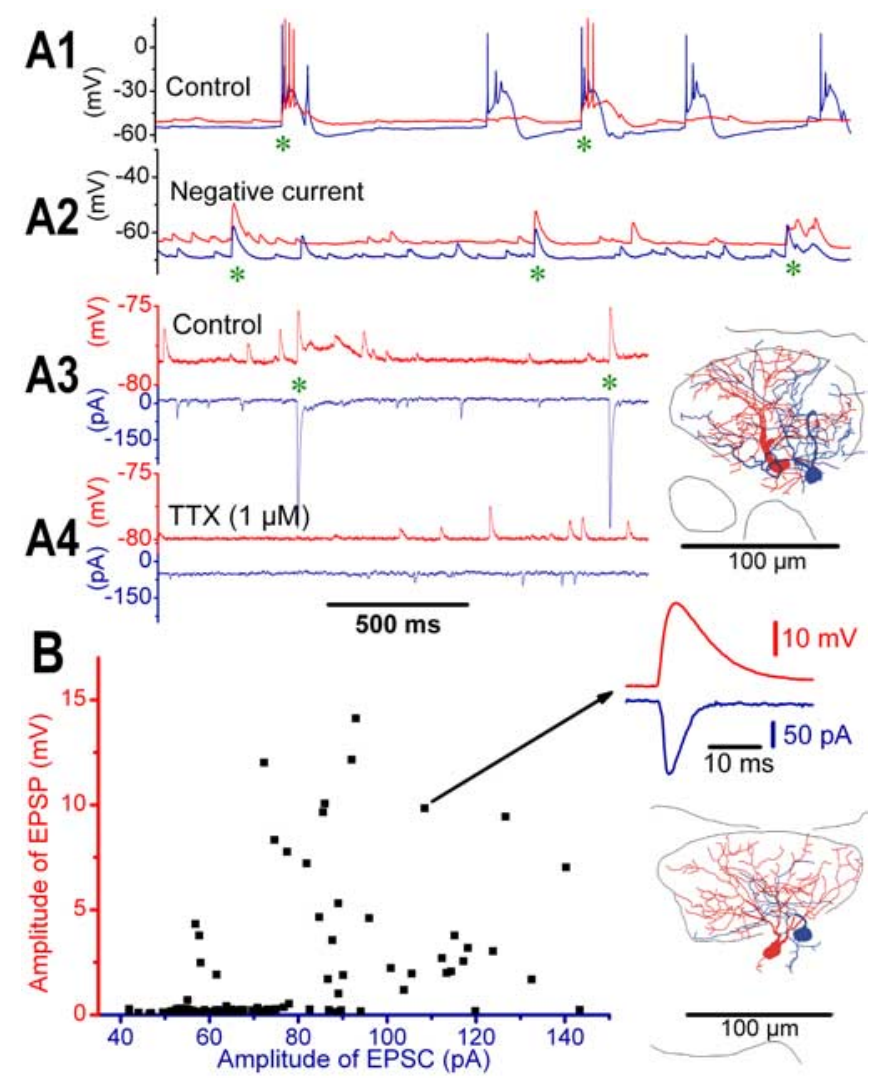

Figure 5. Synchronization in burst firing is attributable in part to a synchronous, action potential-dependent excitatory input. $\boldsymbol{A}, \boldsymbol{B}$, Simultaneous recordings from two pairs of ET cells whose dendrites ramify in the same glomerulus. Red and blue traces correspond to recordings of the two cells, respectively; the blue cell was subsequently recorded in voltage-clamp mode (bottom 2 panels). A1, The two cells exhibited synchronous spike bursts at resting potential; asterisks here and in the panels below indicate synchronous events. $\boldsymbol{A} \mathbf{2}$, When both cells were hyperpolarized using current injection, they displayed synchronous EPSPs. A3, The synchronous $\mathrm{EPSP} / \mathrm{Cs}$ were relatively large and disappeared in TTX $(\boldsymbol{A 4})$; reconstruction at right shows that the two ET cells were associated with the same glomerulus. $\boldsymbol{B}$, Traces obtained from two other simultaneously recorded ET cells (first cell, current-clamp recording in red; second ET cell, voltage-clamp recordings at an HP of -60 in blue); a 40 pA EPSC threshold was used for triggering because larger EPSCS are more likely to be driven by action potentials in presynaptic terminals. The scatter plot from such recordings shows that EPSCs smaller than $80 \mathrm{pA}$ in the ET cell (blue) were rarely associated with a corresponding EPSP in the other ET cell (red; i.e., the amplitude of EPSPs is near $0 \mathrm{mV}$ ). In contrast, when the EPSC amplitude exceeded $80 \mathrm{pA}$, there was typically a large synchronous EPSP in the red cell (inset). Reconstruction at right shows that the two ET cells were associated with the same glomerulus.

of correlated IPSCs. The frequency of the synchronous IPSCs (i.e., onset times $<500 \mu$ s apart) was $0.24 \pm 0.04 \mathrm{IPSC} / \mathrm{s}$. The synchronous IPSCs in all four ET cell pairs analyzed ( $n=8$ cells) had slightly larger mean amplitude $(21.1 \pm 2.4$ pA; range, $11.5-$ $22.1 \mathrm{pA})$ than asynchronous IPSCs (16.8 $\pm 1.7 \mathrm{pA}$; range, $10.1-$ $24.3 \mathrm{pA} ; p=0.01)$. Together, these results indicate that ET cells of the same glomerulus receive coordinated inhibitory input, some of which $(13 \pm 4 \%$ is the ratio between the area of the narrow and broad correlations; $n=4$ ) occur synchronously and may thus originate from the same PG cell(s).

In three of three ET cell pairs with correlated IPSCs, application of APV $(50 \mu \mathrm{M})$ significantly reduced $(p<0.05)$ the peak coefficient of correlation. Subsequent application of CNQX (10 $\mu \mathrm{M})$ eliminated IPSC bursting and abolished $(p<0.05)$ synchrony and correlation [control, $C$ (current) $=0.43 \pm 0.09$; APV, $C($ current $)=0.28 \pm 0.11$; APV plus CNQX, $C$ (current) $=0.07 \pm$ 0.01] (Fig. $6 B$ ). Therefore, activation of AMPA (or kainate) re- ceptors is essential for driving the synchronous bursting inhibitory activity of PG cells.

The mean frequency of synchronous EPSCs (0.38 EPSC/s) in ET cells (above) is comparable with the frequency of spontaneous bursts of IPSCs ( 0.43 burst/s). Therefore, there should be a correlation between large synchronous EPSCs and bursts of IPSCs in ET cell of the same glomerulus. This was tested by recording simultaneously EPSCs and IPSCs from seven ET cell pairs at an $\mathrm{HP}$ of $-30 \mathrm{mV}$ (Fig. 6D). All membrane current crosscorrelograms had a significant positive peak $[C$ (current) $=$ $3.24 \pm 0.06$; range, $0.19-0.52$ ] at zero time lag. In six of the seven ET cell pairs, the cross-correlograms were biphasic, exhibiting a significant anti-peak $[C$ (current) $=-0.97 \pm 0.02$; range, -0.05 to -0.15 ] (Fig. $6 E$ ) at lag time of $88 \pm 10 \mathrm{~ms}$ (range, $72-126 \mathrm{~ms}$ ). The anti-peaks represent the correlation between large EPSCs (inward currents) in one cell and the subsequent burst of IPSCs (outward currents) in the second cell. This indicates that excitatory and inhibitory inputs are temporally correlated in ET cells of the same glomerulus.

We investigated whether glomerular affiliation is essential for synchrony. Eight ET cell pairs (soma $<100 \mu \mathrm{m}$ apart) affiliated with adjacent glomeruli were examined to determine whether they exhibit synchronous spontaneous activity (Fig. 7). Crosscorrelograms of the spikes trains (extracellular recordings) or the membrane currents (intracellular recordings) at an $\mathrm{HP}$ of -60 $\mathrm{mV}$ (EPSC recordings) and an $\mathrm{HP}$ of $0 \mathrm{mV}$ (IPSC recordings) revealed no significant correlations at zero lag time, suggesting the absence of synchronous activity in these ET cells. However, in two of eight pairs, a significant but relatively small and delayed correlation (lag time $>100 \mathrm{~ms} ; C<0.3$; data not shown) was observed between the bursts of IPSCs, suggesting that some spontaneous activity might propagate slowly to adjacent glomeruli. Therefore, the present findings for ET cells are similar to those obtained for mitral cells (Carlson et al., 2000; Schoppa and Westbrook, 2002), in that synchronous activity is restricted to those cells that have dendrites in the same glomerulus.

\section{Evoked and spontaneous gap junction currents among ET cells}

Electrotonic coupling through gap junctions plays an important role in synchronizing neuronal activity (Perez Velazquez and Carlen, 2000). We asked therefore whether ET cells of the same glomerulus are coupled by gap junctions. Whole-cell voltageclamp recordings were made from ET-ET cell pairs of the same glomerulus, using pipettes containing cesium and QX-314. Each cell was stimulated with a positive voltage step ( $100 \mathrm{~ms}$ from -60 to $-20 \mathrm{mV}$ ). In 5 of the 10 ET cell pairs tested, stimulation of one cell produced a slow inward current in the other cell (mean peak amplitude, $6.7 \pm 0.9 \mathrm{pA}$; range, $4-10 \mathrm{pA} ; n=10$ cells from 5 pairs). Moreover, in 5 of 20 ET cells stimulated, a post-pulse inward current was produced in the same cell (Fig. 8C). These evoked slow inward currents persisted in CNQX and APV but were reduced or blocked by carbenoxolone ( $300 \mu \mathrm{M} ; n=4$ pairs or 8 cells) (Fig. $8 E$ ), suggesting that they are mediated mainly by electrical coupling. The effects of carbenoxolone were very weakly reversible ( $<30 \%$ after 30 min washout; data not shown) (Schoppa and Westbrook, 2002).

Because negative voltage pulses are unlikely to trigger transmitter release, an outward current generated in the second cell is most likely attributable to gap junction coupling. Therefore, we generated $-50 \mathrm{mV}$ steps (from -60 to $-110 \mathrm{mV}, 200 \mathrm{~ms}$ duration) and measured the current evoked in the other cell. In four of nine same glomerulus ET cell pairs, an outward current was pro- 
duced in the second cell (peak amplitude of $5.1 \pm 0.4 \mathrm{pA}$; range, $3-7 \mathrm{pA} ; n=8$ cells from the 4 pairs) (Fig. $8 D$ ). This outward current was significantly inhibited by carbenoxolone (control, $4.0 \pm 0.3 \mathrm{pA}$; carbenoxolone, $1.7 \pm 0.1 \mathrm{pA} ; n=5 ; p<$ 0.001) (Fig. 8F). The mean junction conductance in ET cells [0.1 nS, calculated using the steady-state current generated in one cell by applying a negative voltage step $(-50 \mathrm{mV}, 200 \mathrm{~ms}$ duration) in the other cell] was an order of magnitude smaller than other electrically coupled neurons in the brain (1.2 nS in retinal cells, Veruki and Hartveit, 2002; 1.6-2 nS in neocortical interneurons, Gibson et al., 1999). The evoked electrotonic current in ET cells reached a steady-state level exponentially with a mean time constant of $82 \pm 13 \mathrm{~ms}$ (range, $43-125 \mathrm{~ms} ; n=8$ cells) (Fig. $8 D$ ). The mean gap junction current (5.1 pA) evoked by $50 \mathrm{mV}$ step pulses would induce $\sim 1 \mathrm{mV}$ hyperpolarization in ET cells (assuming a mean input resistance of 194 $\mathrm{M} \Omega$ ) (Hayar et al., 2004a). This 50-to-1 $\mathrm{mV}$ attenuation indicates a coupling ratio of $\sim 2 \%$, which is comparable with the electrical coupling ratio $(0.5-5 \%)$ between mitral cells (Schoppa and Westbrook, 2002). These results suggest that gap junctions of relatively low conductance may coordinate the activity of ET cells.

We next investigated whether spontaneous gap junction currents are involved in ET cell synchronous activity, which persists in the presence of fast synaptic blockers (Hayar et al., 2004b). Synchronous activity is not attributable to calcium-dependent transmitter release because application of the calcium channel blockers cadmium $(100 \mu \mathrm{M})$ and nickel (100 $\mu \mathrm{M})$ did not change significantly the spike train correlations [control, $C$ (spikes) $=$ $3.0 \pm 0.9$ vs cadmium plus nickel, $C$ (spikes) $=3.7 \pm 0.8 ; p=0.2 ; n=4$ ] (Fig. $9 A)$. Application of the fast synaptic blockers revealed in 11 of 21 (52\%) ET cells rhythmic membrane potential or current oscillations (mean frequency, $1.3 \pm 0.2$ $\mathrm{Hz}$; range, $0.6-2.6 \mathrm{~Hz} ; n=11$ ) (Fig. $9 B, C)$. As shown in Figure 9C, spikelets were superimposed on these slow oscillations. Because these spikelets persisted in the calcium channel blockers cadmium $(100-300 \mu \mathrm{M})$ and nickel $(100-1000 \mu \mathrm{M})$, they are unlikely to be calcium spikes or postsynaptic potentials induced by calcium-dependent neurotransmitter release.

Both spikelets and membrane oscillations were blocked by the gap junction blocker carbenoxolone, which progressively reduced both the frequency and magnitude of the oscillations from $1.7 \pm 0.4 \mathrm{~Hz}$ in control to $1.2 \pm 0.2 \mathrm{~Hz}$ after 3 min of application $(p<0.05 ; n=5)$ (Fig. 9D) and blocked
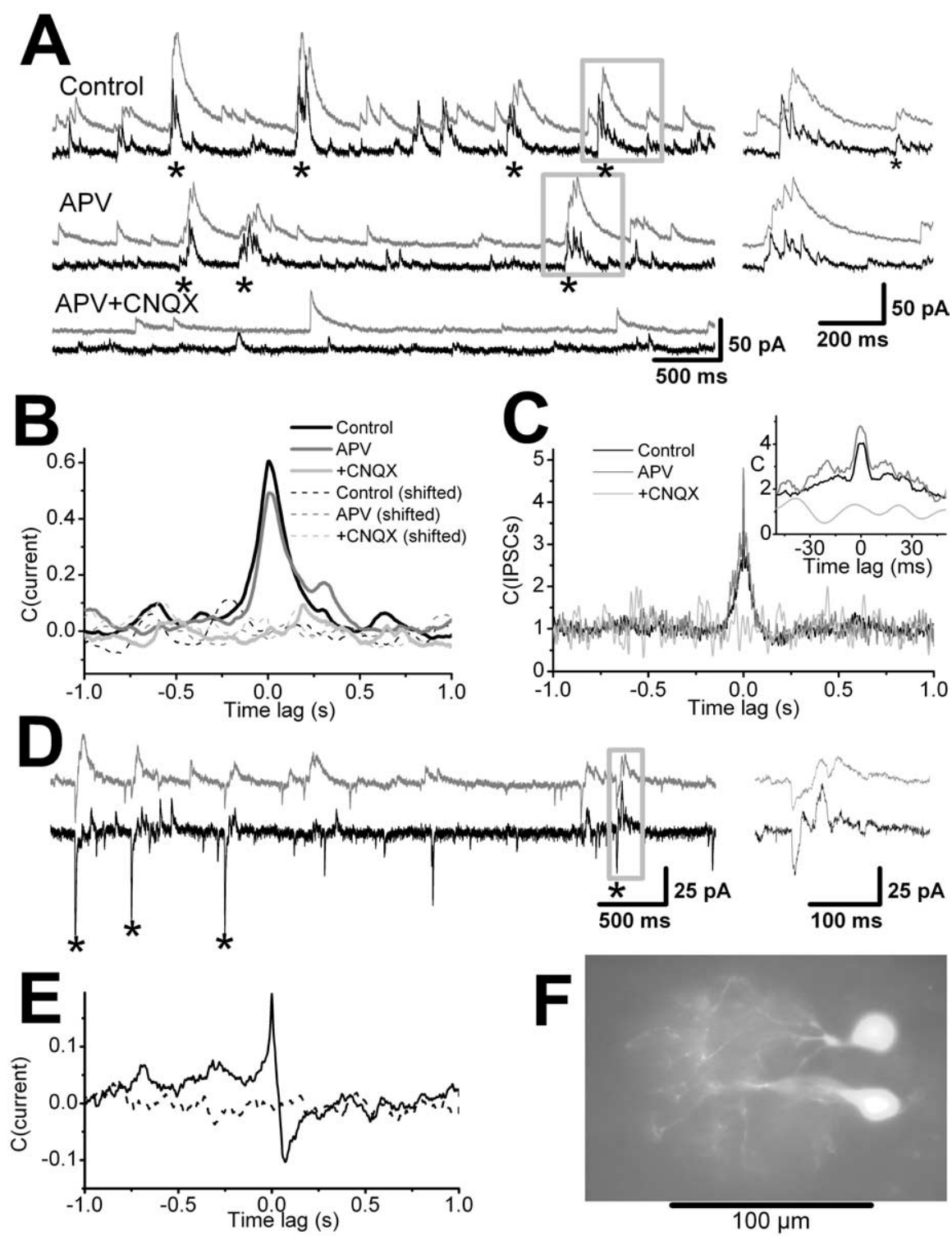

Figure 6. Synchronous bursts of IPSCs in ET cell pairs. All data in this figure were obtained from the same ET cell pair. $\boldsymbol{A}$, Simultaneous whole-cell voltage-clamp recordings (HP of $0 \mathrm{mV}$ ) from two ET cells (gray and black traces, respectively) show synchronous IPSC bursts (asterisks) before and during application of APV (50 $\mu \mathrm{m})$. Note that, although APV reduced burst frequency, bursts remained synchronous in the two cells. Additional application of CNQX eliminated the IPSC burst synchrony. Areas highlighted in rectangles are shown at faster timescale at right. $\boldsymbol{B}$, Membrane current cross-correlograms $(50 \mathrm{~s}$ recording samples, 2 ms bins) in control, APV, and after additional application of CNQX. The cross-correlograms of currents indicate the degree to which changes in membrane current of each cell were correlated (see Materials and Methods). Note the significant peak (confidence limit $>99.73 \%$ ) at zero lag time in control and APV. There was no significant correlation after application of CNQX. The $99.73 \%$ confidence limit was determined by cross-correlating traces shifted by $5 \mathrm{~s}$ (dashed traces; see Materials and Methods). C, Cross-correlogram of the IPSC trains ( 5 min recording samples, $1 \mathrm{~ms}$ bins) show a significant narrow peak (see inset) at zero time lag, indicating synchronous IPSCS in the two recorded cells. The cross-correlograms of IPSCs indicate how frequently one cell exhibits synchronous IPSCs with another cell compared with chance (see Materials and Methods). The narrow peak was superimposed on a broader peak corresponding to the longer duration correlated IPSC bursts. CNQX abolished correlation and synchrony of IPSCs. D, Simultaneous whole-cell voltage-clamp recordings ( $\mathrm{HP}$ of $-30 \mathrm{mV}$ ) from the same two $\mathrm{ET}$ cells showing synchronous EPSCs followed by IPSC bursts; recording highlighted in rectangle is shown at faster timescale at right. Recordings obtained before the application of synaptic blockers in $\boldsymbol{A}$. $\boldsymbol{E}$, Membrane current cross-correlogram ( $50 \mathrm{~s}$ sample, bin of $2 \mathrm{~ms}$ ) at an HP of $-30 \mathrm{mV}$ shows the significant biphasic cross-correlation (positive peak $C=0.19$ at 0 lag time; negative peak $C=0.10$ at 72 ms lag time); dashed trace represents the cross-correlogram of the two currents after shifting the traces by $5 \mathrm{~s}$. F, Photograph showing Lucifer yellow labeling of the two recorded cells. them after 7-10 min of continuous application. Carbenoxolone was reported to inhibit synaptic transmission by blocking calcium channels (Vessey et al., 2004). However, this side effect of carbenoxolone could not have eliminated the spikelets and mem- 

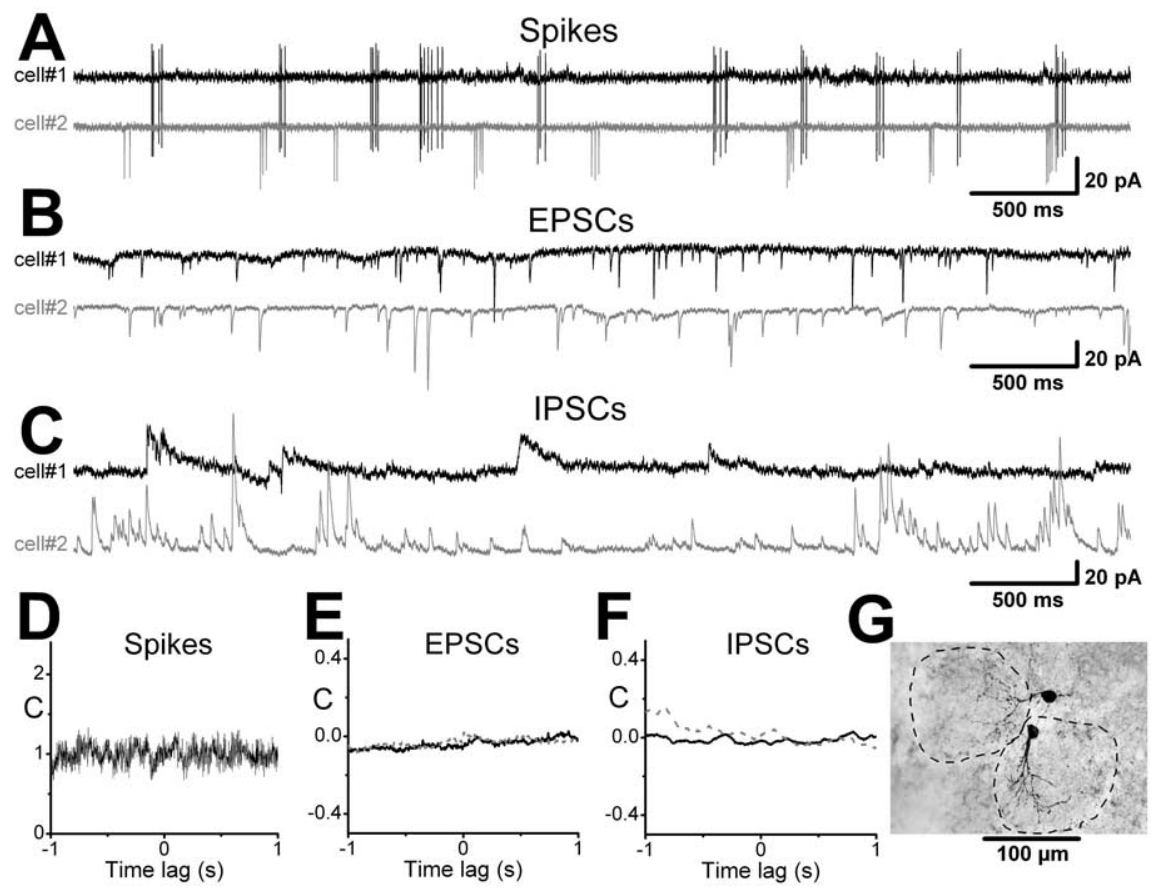

Figure 7. Activity of ET cells affiliated with adjacent glomeruli is not correlated. All data presented in this figure were obtained from the same ET cell pair. $\boldsymbol{A}$, Simultaneous extracellular recordings were obtained from two ET cells, and then the same two cells were recorded in whole-cell configuration $(\boldsymbol{B})$ in voltage clamp ( $\mathrm{HP}$ of $-60 \mathrm{mV}$ ) using electrodes containing $\mathrm{CsMeSO}_{3}$ and QX-314. Note the absence of synchronous EPSCs. $\boldsymbol{C}$, Recordings from the same cells at an HP of $0 \mathrm{mV}$ show no synchronous IPSCS. D, Cross-correlograms of the spike trains ( 5 min sample, bin of $1 \mathrm{~ms}$ ) show that action potentials were not correlated. $\boldsymbol{E}, \boldsymbol{F}$, Membrane current cross-correlograms ( 50 s samples, 2 ms bins) show that there was no correlation of EPSCs ( $\boldsymbol{E}$; HP of $-60 \mathrm{mV})$ or IPSCs (F; $\mathrm{HP}$ of $0 \mathrm{mV}$ ). The gray dashed traces indicate membrane current traces after shifting traces by $5 \mathrm{~s}$ (to determine significance, see Materials and Methods). $\mathbf{G}$, Biocytin staining indicated that the dendrites of the two ET cells were affiliated with different glomeruli (dashed lines).

brane current oscillations because, as shown above, they persisted in the presence of fast synaptic blockers and calcium channel blockers.

Four of seven ET cell pairs of the same glomerulus exhibited membrane current oscillations (mean frequency, $1.4 \pm 0.4 \mathrm{~Hz}$ ) during application of synaptic blockers. In each of these four ET cell pairs, the frequencies of membrane current oscillations were identical in both cells $(p=0.95)$. Moreover, there was a significant membrane current correlation that was blocked by carbenoxolone in all four pairs $[C$ (current $)=0.48 \pm 0.03$ at lag time 0 ms; range, 0.42-0.53] (Fig. 9D). These results suggest that gap junctions might be involved in synchronizing oscillatory and bursting activity of ET cells of the same glomerulus.

\section{Discussion}

The present results demonstrate that the activity of ET cells of the same glomerulus is coordinated by both chemical and electrical synapses. ET cells whose dendrites ramify in the same but not different glomeruli exhibit synchronous synaptic inputs (fast and slow EPSP/Cs, bursts of IPSCs), which may contribute to their correlated activity. During blockade of fast synaptic transmission, ET cells of the same glomerulus continue to exhibit synchronous bursting, which appears to be mediated by synchronous slow and fast electrotonic currents that are sensitive to a gap junction blocker.

\section{Electrical coupling among ET cells}

Gap junction coupling can play an important role in the generation and stabilization of bursting oscillatory behavior (Skinner et al., 1999). The present results show that synchronous gap junction currents can be produced in pairs of ET cells associated with the same glomerulus. Thus, ET cells may be synchronized in part via electrical coupling with other ET cells or possibly with the apical tufts of tufted/mitral cells. Indeed, electron microscopic studies suggest an indirect coupling between mitral cells via intervening interneuronal processes in addition to the direct gap junction coupling between them (Kosaka and Kosaka, 2004). These intervening processes originate from GABA-negative and tyrosine hydroxylase-negative uncharacterized neurons that receive synapses from olfactory nerve terminals and are therefore likely to be the dendrites of ET cells (Kosaka and Kosaka, 2003, 2005). Therefore, both ultrastructural and electrophysiological studies obtained so far indicate that mitral/tufted cells and ET cells might form gap junctions among themselves and among each other. ET cells had relatively small gap junction conductance $(0.1 \mathrm{nS})$. Unlike mitral cells, which exhibit a narrow window of spike-to-spike correlation (Schoppa and Westbrook, 2002), ET cells exhibit a broader window of burst-toburst correlation. The narrow window of correlation among mitral cells is attributable to the fact that mitral cell spikes induced fast EPSPs in other mitral cells (Schoppa and Westbrook, 2002; Urban and Sakmann, 2002; Christie et al., 2005). In contrast, ET cells seem to communicate mainly via slow inward currents produced by gap junctions with relatively low conductance. A potential function of gap junctions in ET cells is to filter fast spiking activity and propagate slow membrane potential oscillations, which are driven mainly by persistent sodium currents (Hayar et al., 2004a).

\section{Synchrony of EPSCs}

The present findings show that the spike bursts of ET cells of the same glomerulus may be synchronized by fast coincident EPSPs, which are relatively large in amplitude and are blocked by TTX (Fig. 5). These synchronous EPSCs probably result from action potential propagation in presynaptic axons or dendrites that provide common input to ET cells of the same glomerulus. Because all ET cells receive monosynaptic input from the olfactory nerve (Hayar et al., 2004b) and their dendrites ramify throughout most of a single glomerulus, it is possible that each olfactory axon arborizes in the glomerulus and establishes synaptic contacts with several ET cells. Moreover, because olfactory nerve bundles express connexin 36 (Zhang and Restrepo, 2003), activity among olfactory nerve fibers converging on the same glomerulus may be synchronized by gap junctions, thereby providing phase-locked input simultaneously to many ET cells. The hypothesis that synchronous EPSCs are produced by olfactory nerve terminals is supported by the findings that olfactory nerve stimulation produced EPSC-IPSC burst sequences identical to those that occur spontaneously. The fast synchronous EPSCs are unlikely to originate from mitral, tufted, or other ET cells for the following rea- 
sons: (1) stimulation of the external plexiform, which would antidromically activate ET cells as well as the apical tufts of mitral and tufted cells, produced only slow EPSCs in ET cells; and (2) stimulation of individual ET cells produced only slow inward currents in other ET cells.

The slow inward current evoked in one ET cell by intracellular stimulation of another ET cell was not significantly affected by CNQX and APV but was attenuated by carbenoxolone, indicating that it is mainly attributable to electrical coupling. This does not rule out the possibility that ET cells may communicate by synaptic transmission. The amount of glutamate released from a single ET cell may be too small to be detected but could become significant when the ensemble of ET cells of the same glomerulus burst synchronously. In contrast, spontaneous slow inward currents, as well as slow currents evoked by stimulation of the olfactory nerve or external plexiform layers, were blocked by glutamate receptor antagonists, suggesting that they may be mediated by glutamate spillover within the glomerulus. Similarly, mitral cells whose tufts are associated with the same glomerulus exhibit synchronous long-lasting depolarizations attributed to a sustained recurrent excitatory synaptic input of glomerular origin (Carlson et al., 2000; Schoppa and Westbrook, 2002; Urban and Sakmann, 2002). The source of glutamate input to mitral cells may in part originate from mitral cells themselves, because their apical tufts could provide glutamatergic input to each other via spillover or direct synaptic contacts (Schoppa and Westbrook, 2002; Urban and Sakmann, 2002). Alternatively, ET cells, which outnumber mitral cells (Shipley et al., 1996) and which generate correlated bursting, may be a source of sustained glutamate release onto mitral cells (supplemental Fig. S1, available at www.jneurosci.org as supplemental material).

\section{Correlated bursts of IPSCs}

Recurrent inhibition can generate synchronized activity in many neural networks (for review, see Jefferys et al., 1996). In mitral cells, Desmaisons et al. (1999) found that the spontaneous synchronous IPSPs can reset the phase of subthreshold membrane oscillations and synchronize the firing of multiple mitral cells. Correlated IPSCs could similarly synchronize the bursting of ET cells. Correlated IPSPs might also contribute to the odor-elicited highfrequency oscillations in the olfactory bulb of adult rats (Fletcher et al., 2005). The intraburst IPSC frequency in ET cells occurs $\sim 50 \mathrm{~Hz}$ (gamma frequency), similar to the frequency of olfactory nerve-evoked local field potential oscillations (mean of $45 \mathrm{~Hz}$ )

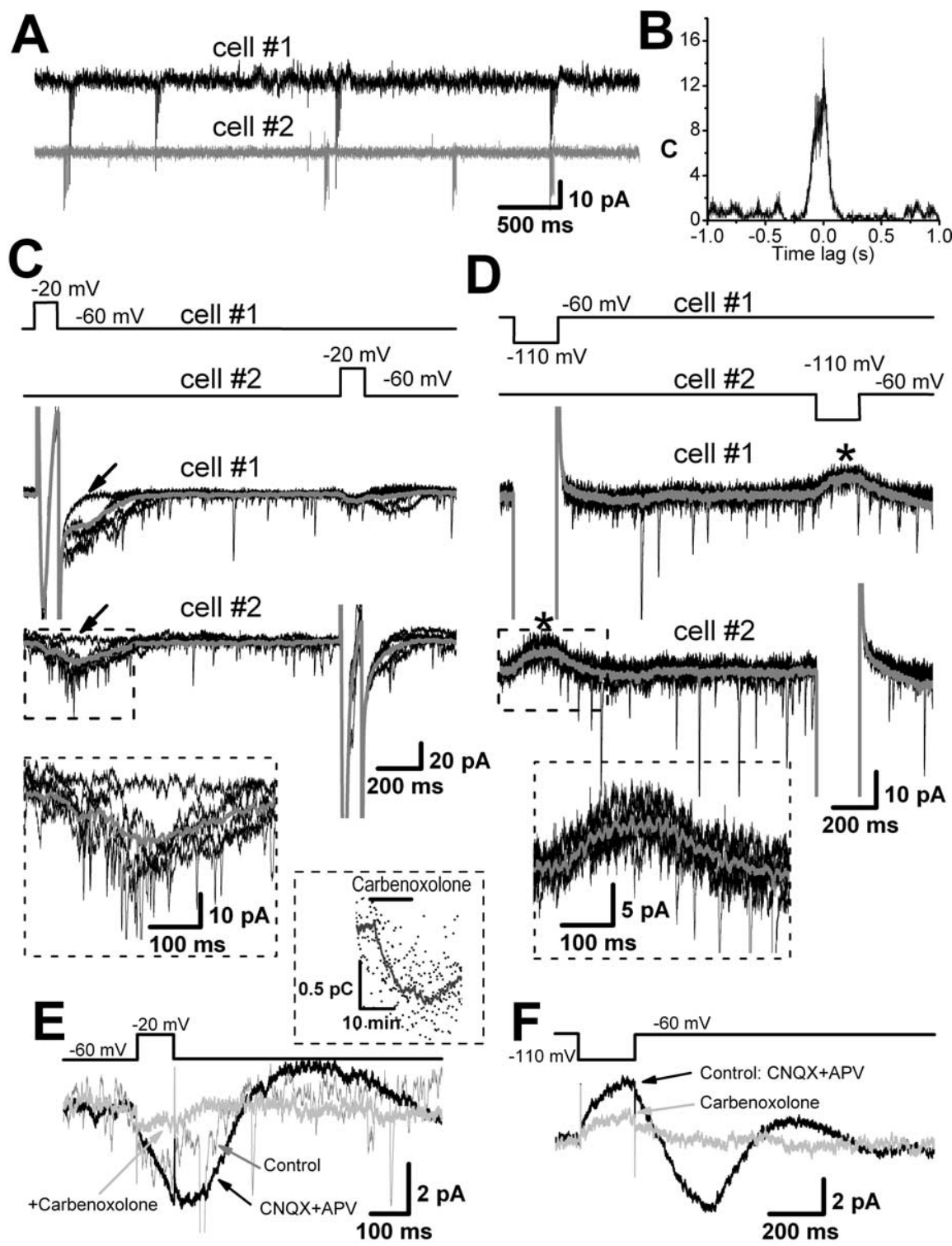

Figure 8. ET cells communicate via gap junctions. $\boldsymbol{A}-\boldsymbol{D}$ were obtained from the same ET cell pair. $\boldsymbol{A}$, Simultaneous extracellular recordings from two ET cells with apparent correlated bursting. $\boldsymbol{B}$, Cross-correlogram of the spike trains ( $5 \mathrm{~min}, 1 \mathrm{~ms}$ bins) shows significant broad synchrony at approximately zero time lag. $\boldsymbol{C}$, Both cells were recorded simultaneously in whole-cell voltageclamp mode at an $\mathrm{HP}$ of $-60 \mathrm{mV}$ using pipettes containing $\mathrm{CsMeSO}_{3}$ and QX-314. Each cell was stimulated with a positive voltage step (100 ms from -60 to $-20 \mathrm{mV}$ ) to generate a calcium current. The calcium currents triggered a slow inward current in the other cell and a post-pulse inward current in the same cell. The occasional failures (arrows) and response variability contrasts with the putative gap junction currents shown in $\boldsymbol{D}$. $\boldsymbol{D}$, The existence of gap junction currents was tested between the two ET cells by generating $50 \mathrm{mV}$ negative voltage step pulses ( $200 \mathrm{~ms}$ from -60 to $-110 \mathrm{mV}$ ) in each cell and measuring the current evoked in the other cell. This produced an outward current in the other cell (asterisks); note that the current exponentially reached a steady-state level of $\sim 10 \mathrm{pA}$. C and $\boldsymbol{D}$ show six representative current traces from each cell in each condition and an average of 20 traces (thick gray line). Areas highlighted in rectangles are expanded in the insets shown at bottom. $\boldsymbol{E}, \boldsymbol{F}$, Recording in an ET cell of responses to application of positive and negative voltage steps in another ET cell affiliated with the same glomerulus. $E$, CNQX and APV blocked the synaptic currents (noisy signal in control) and revealed an underlying inward current that extended beyond the stimulation pulse. The evoked current was inhibited by carbenoxolone $(300 \mu \mathrm{m})$, and this effect was only partially reversible, as shown in inset at top right (the line represents a running average of the electric charge of 30 evoked currents). $\boldsymbol{F}$, The negative voltage steps produced an outward current and a rebound oscillation that were inhibited by carbenoxolone. Each trace is an average of 50 traces in each condition.

(Lagier et al., 2004) recorded in the mitral cell layer and attributed to rhythmic dendrodendritic granule-to-mitral cell inhibition. The bursts of IPSCs in ET cells may reflect the temporal and spatial summation of inhibitory inputs originating from several presynaptic PG cells. The IPSCs hyperpolarize or shunt the dendrites of ET cells. This will limit the amount of glutamate released 


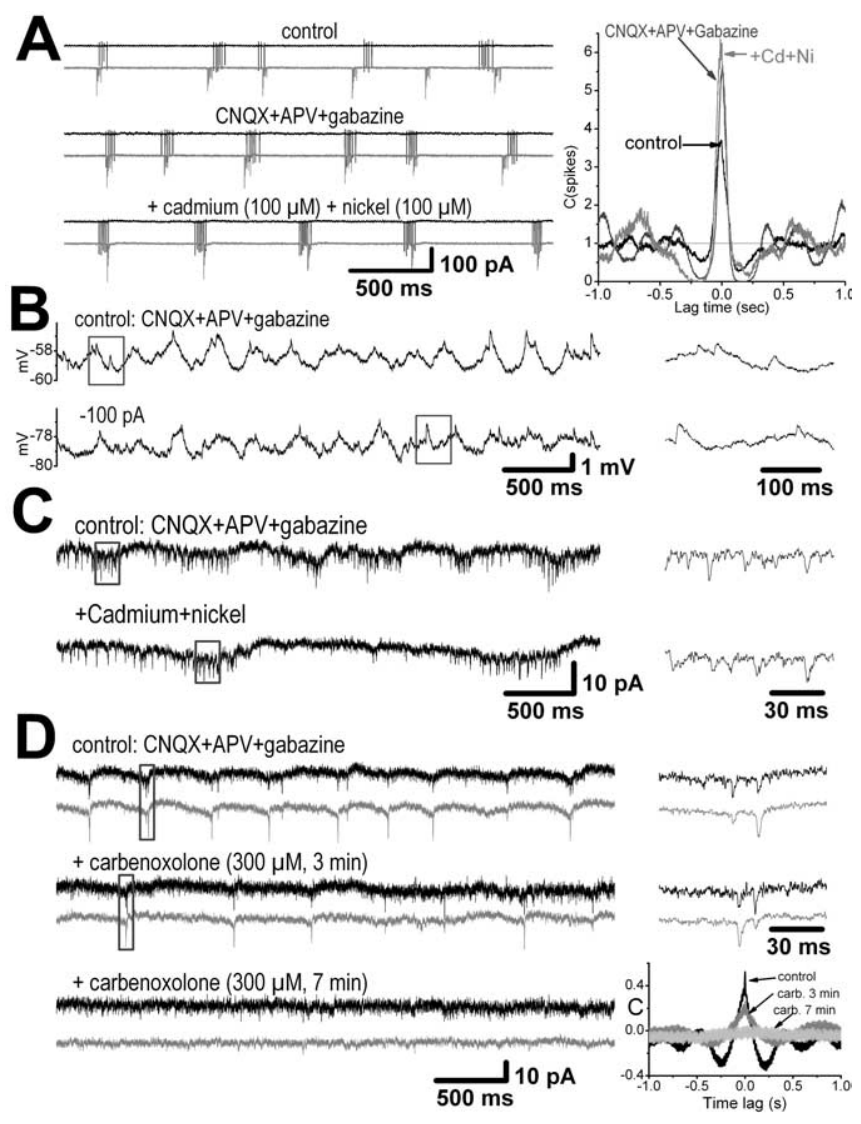

Figure 9. ET cells of the same glomerulus exhibit synchronous, spontaneous gap junction currents. $\boldsymbol{A}$, Simultaneous extracellular recordings from two ET cells showing spontaneous bursting discharge before and during application of fast synaptic blockers and then after additional application of the calcium channel blockers cadmium and nickel. Spike train crosscorrelograms ( 5 min sample in each condition) at right show that burst synchrony persisted in the presence of blockers of fast synaptic transmission and calcium channels. $\boldsymbol{B}$, Current-clamp recordings from an ET cell in the presence of synaptic blockers using a pipette that contains QX-314 (10 mm). Note spontaneous membrane potential oscillations and small spikelets. Hyperpolarization (bottom trace) did not affect the frequency of the oscillations or the spikelets. Recording samples indicated by rectangles are shown at faster timescale at right in this and bottom panels. C, Recordings from another ET cell in voltage clamp (HP of $-60 \mathrm{mV}$, using pipette containing $\mathrm{CSMeSO}_{3}$ and $\mathrm{QX}$-314) show that the spikelets and the membrane current oscillations persisted in the presence of the calcium channel blockers. $D$, Simultaneous recordings from an ET cell pair recorded in the presence of synaptic blockers. Note the synchrony between the membrane current oscillations as well as between the spikelets. The gap junction blocker carbenoxolone progressively decreased the frequency and amplitude of the synchronous oscillations and spikelets before a complete blockade occurred after $7 \mathrm{~min}$. Bottom right panel shows the membrane current cross-correlogram ( 50 s samples, 2 ms bins) in control and during application of carbenoxolone.

by ET cells and, as a consequence, reduce the amount of glutamate spillover in the glomerulus. Because IPSCs and slow EPSCs occur in ET cells within $\sim 100 \mathrm{~ms}$ after olfactory nerve stimulation, IPSCs would also oppose or shunt the slow EPSCs that are attributable to glutamate spillover. Because olfactory nerve inputs may target dendritic loci in the vicinity of PG-ET synapses, PG-derived IPSCs bursts may also reduce the sensitivity of ET cells to sensory input.

PG cells may also mediate local intraglomerular lateral inhibition among ET cells (Murphy et al., 2005), i.e., one ET cell could excite a PG cell, which in turn inhibits another ET cell, in a manner similar to mitral-granule-mitral (M-G-M) dendrodendritic lateral inhibition (Mori and Takagi, 1978; Jahr and Nicoll, 1980; Nowycky et al., 1981; Isaacson and Strowbridge, 1998;
Schoppa et al., 1998; Urban and Sakmann, 2002). Lateral and feedback inhibition of mitral cells is primarily dependent on activation of NMDA receptors located on granule cells (Chen et al., 2000; Halabisky et al., 2000; Isaacson, 2001). In contrast, the present results indicate that the correlated bursts of IPSCs in ET cells do not require NMDA receptor activation. Therefore, the correlated spike bursts of ET cells drive non-NMDA receptormediated EPSPs in PG cells (Hayar et al., 2004b), which synchronously release GABA onto ET cells. This spike-EPSC-IPSC bursting cycle is a regenerative process attributable to persistent sodium channels that drive rhythmic bursting in ET cells (Hayar et al., 2004a).

\section{Functional operations of the intraglomerular network}

ET and PG cells of the same glomerulus form an ensemble of neurons that share and process a common input and provide an amplified output proportional to glomerular activation. ET cells receive monosynaptic sensory input (Hayar et al., 2004b). PG cells are excited by and in turn provide intraglomerular feedback and lateral inhibition of ET cells. This arrangement is similar to the $\mathrm{M}-\mathrm{G}-\mathrm{M}$ circuit in which mitral cells excite granule cells, which in turn provide feedback and lateral inhibition of other mitral cells. The M-G-M circuit is generally thought to provide contrast enhancement of strongly versus weakly activated glomeruli, i.e., interglomerular spatial contrast enhancement. It is less obvious what functional role would be served by intraglomerular spatial contrast enhancement via the ET-PG-ET circuit. However, in addition to its role in spatial contrast enhancement, the $\mathrm{M}-\mathrm{G}-\mathrm{M}$ circuit also provides a temporal windowing function via feedback inhibition of mitral cells. Thus, after strong excitation, $\mathrm{M}-\mathrm{G}-\mathrm{M}$ feedback inhibition temporarily reduces mitral cell excitability, thus reducing sensitivity to sensory input. The ETPG-ET circuit is well suited to provide a similar intraglomerular temporal windowing function. Olfactory nerve input triggers synchronous bursting among ET cells of the same glomerulus (Hayar et al., 2004a). ET cell bursts, in turn, may synchronize activity among mitral/tufted cells via glutamate spillover and gap junctions. PG cells, which are activated by ET cell bursts (Hayar et al., 2004a), provide synchronous inhibitory feedback to ET cells, thereby creating a refractory period during which the glomerulus is less responsive to sensory input. GABA and dopamine released by PG cells also causes presynaptic inhibition of ON terminals, which augments the refractory period generated by the ETPG-ET circuit (Ennis et al., 2001; Wachowiak et al., 2005). Thus, the intraglomerular circuit may function first to amplify olfactory nerve input and then to generate a refractory window, within which sensory inputs are integrated to synchronize glomerular output. This intraglomerular windowing function, taken with the center-surround inhibitory function mediated by interglomerular connections (Aungst et al., 2003), endows the glomerular network with the capacity to provide both temporal and spatial enhancement of odor signals at the initial site of synaptic integration in the olfactory system.

\section{References}

Aertsen AM, Gerstein GL, Habib MK, Palm G (1989) Dynamics of neuronal firing correlation: modulation of "effective connectivity." J Neurophysiol 61:900-917.

Aungst JL, Heyward PM, Puche AC, Karnup SV, Hayar A, Szabo G, Shipley MT (2003) Center-surround inhibition among olfactory bulb glomeruli Nature 426:623-629.

Carlson GC, Shipley MT, Keller A (2000) Long-lasting depolarizations in mitral cells of the rat olfactory bulb. J Neurosci 20:2011-2021.

Chen WR, Xiong W, Shepherd GM (2000) Analysis of relations between 
NMDA receptors and GABA release at olfactory bulb reciprocal synapses. Neuron 25:625-633.

Christie JM, Bark C, Hormuzdi SG, Helbig I, Monyer H, Westbrook GL (2005) Connexin 36 mediates spike synchrony in olfactory bulb glomeruli. Neuron 46:761-772.

Desmaisons D, Vincent JD, Lledo PM (1999) Control of action potential timing by intrinsic subthreshold oscillations in olfactory bulb output neurons. J Neurosci 19:10727-10737.

Ennis M, Zhou FM, Ciombor KJ, Aroniadou-Anderjaska V, Hayar A, Borrelli E, Zimmer LA, Margolis F, Shipley MT (2001) Dopamine D2 receptormediated presynaptic inhibition of olfactory nerve terminals. J Neurophysiol 86:2986-2997.

Fletcher ML, Smith AM, Best AR, Wilson DA (2005) High-frequency oscillations are not necessary for simple olfactory discriminations in young rats. J Neurosci 25:792-798.

Gerstein GL, Perkel DH (1972) Mutual temporal relationships among neuronal spike trains. Statistical techniques for display and analysis. Biophys J 12:453-473.

Gibson JR, Beierlein M, Connors BW (1999) Two networks of electrically coupled inhibitory neurons in neocortex. Nature 402:75-79.

Halabisky B, Friedman D, Radojicic M, Strowbridge BW (2000) Calcium influx through NMDA receptors directly evokes GABA release in olfactory bulb granule cells. J Neurosci 20:5124-5134.

Hayar A, Karnup S, Shipley MT, Ennis M (2004a) Olfactory bulb glomeruli: external tufted cells intrinsically burst at theta frequency and are entrained by patterned olfactory input. J Neurosci 24:1190-1199.

Hayar A, Karnup S, Ennis M, Shipley MT (2004b) External tufted cells: a major excitatory element that coordinates glomerular activity. J Neurosci 24:6676-6685.

Isaacson JS (2001) Mechanisms governing dendritic gamma-aminobutyric acid (GABA) release in the rat olfactory bulb. Proc Natl Acad Sci USA 98:337-342.

Isaacson JS, Strowbridge BW (1998) Olfactory reciprocal synapses: dendritic signaling in the CNS. Neuron 20:749-761.

Jahr CE, Nicoll RA (1980) Dendrodendritic inhibition: demonstration with intracellular recording. Science 207:1473-1475.

Jefferys JG, Traub RD, Whittington MA (1996) Neuronal networks for induced " $40 \mathrm{~Hz}$ " rhythms. Trends Neurosci 19:202-220.

Karnup S, Stelzer A (1999) Temporal overlap of excitatory and inhibitory afferent input in guinea-pig CA1 pyramidal cells. J Physiol (Lond) 516:485-504.

Kosaka T, Kosaka K (2003) Neuronal gap junctions in the rat main olfactory bulb, with special reference to intraglomerular gap junctions. Neurosci Res 45:189-209.

Kosaka T, Kosaka K (2004) Neuronal gap junctions between intraglomerular mitral/tufted cell dendrites in the mouse main olfactory bulb. Neurosci Res 49:373-378.

Kosaka T, Kosaka K (2005) Intraglomerular dendritic link connected by gap junctions and chemical synapses in the mouse main olfactory bulb: electron microscopic serial section analyses. Neuroscience 131:611-625.

Kosaka T, Hataguchi Y, Nagatsu I, Wu J-Y (1985) Coexistence of immunoreactivities for glutamate decarboxylase and tyrosine hydroxylase in some neurons in the periglomerular region of the rat main olfactory bulb: possible coexistence of gamma-aminobutyric acid (GABA) and dopamine. Brain Res 343:166-171.

Lagier S, Carleton A, Lledo PM (2004) Interplay between local GABAergic interneurons and relay neurons generates gamma oscillations in the rat olfactory bulb. J Neurosci 24:4382-4392.

Laurent G (2002) Olfactory network dynamics and the coding of multidimensional signals. Nat Rev Neurosci 3:884-895.

Lestienne R (1999) Intrinsic and extrinsic neuronal mechanisms in temporal coding: a further look at neuronal oscillations. Neural Plast 6:173-189.
Mann-Metzer P, Yarom Y (1999) Electrotonic coupling interacts with intrinsic properties to generate synchronized activity in cerebellar networks of inhibitory interneurons. J Neurosci 19:3298-3306.

Menendez de la Prida L (2003) Control of bursting by local inhibition in the rat subiculum in vitro. J Physiol (Lond) 549:219-230.

Mori K, Takagi SF (1978) An intracellular study of dendrodendritic inhibitory synapses on mitral cells in the rabbit olfactory bulb. J Physiol (Lond) 279:569-588.

Murphy GJ, Darcy DP, Isaacson JS (2005) Intraglomerular inhibition: signaling mechanisms of an olfactory microcircuit. Nat Neurosci 8:354-364.

Nowycky MC, Mori K, Shepherd GM (1981) GABAergic mechanisms of dendrodendritic synapses in isolated turtle olfactory bulb. J Neurophysiol 46:639-648.

Perez Velazquez JL, Carlen PL (2000) Gap junctions, synchrony and seizures. Trends Neurosci 23:68-74.

Perkel DH, Gerstein GL, Moore GP (1967) Neuronal spike trains and stochastic point processes. I. The single spike train. Biophys J 7:391-418.

Pinching AJ, Powell TP (1971a) The neuron types of the glomerular layer of the olfactory bulb. J Cell Sci 9:305-345.

Pinching AJ, Powell TP (1971b) The neuropil of the glomeruli of the olfactory bulb. J Cell Sci 9:347-377.

Ribak CE, Vaughn JE, Saito K, Barber R, Roberts E (1977) Glutamate decarboxylase localization in neurons of the olfactory bulb. Brain Res 126:1-18.

Schoppa NE, Urban NN (2003) Dendritic processing within olfactory bulb circuits. Trends Neurosci 26:501-506.

Schoppa NE, Westbrook GL (2002) AMPA autoreceptors drive correlated spiking in olfactory bulb glomeruli. Nat Neurosci 5:1194-1202.

Schoppa NE, Kinzie JM, Sahara Y, Segerson TP, Westbrook GL (1998) Dendrodendritic inhibition in the olfactory bulb is driven by NMDA receptors. J Neurosci 18:6790-6802.

Shipley MT, McLean JH, Zimmer LA, Ennis M (1996) The olfactory system. In: Handbook of chemical neuroanatomy, Vol 12, Integrated systems of the CNS, Pt III (Björklund A, Hökfelt T, Swanson LW, eds), pp 469-573. Amsterdam: Elsevier.

Singer W (1999) Neuronal synchrony: a versatile code for the definition of relations? Neuron 24:49-65, 111-125.

Singer W, Gray CM (1995) Visual feature integration and the temporal correlation hypotheses. Annu Rev Neurosci 18:555-586.

Skinner FK, Zhang L, Velazquez JL, Carlen PL (1999) Bursting in inhibitory interneuronal networks: a role for gap-junctional coupling. J Neurophysiol 81:1274-1283.

Urban NN, Sakmann B (2002) Reciprocal intraglomerular excitation and intra- and interglomerular lateral inhibition between mouse olfactory bulb mitral cells. J Physiol (Lond) 542:355-367.

Veruki ML, Hartveit E (2002) Electrical synapses mediate signal transmission in the rod pathway of the mammalian retina. J Neurosci 22:10558-10566.

Vessey JP, Lalonde MR, Mizan HA, Welch NC, Kelly ME, Barnes S (2004) Carbenoxolone inhibition of voltage-gated $\mathrm{Ca}$ channels and synaptic transmission in the retina. J Neurophysiol 92:1252-1256.

Wachowiak M, McGann JP, Heyward PM, Shao Z, Puche AC, Shipley MT (2005) Inhibition of olfactory receptor neuron input to olfactory bulb glomeruli mediated by suppression of presynaptic calcium influx. J Neurophysiol, in press.

Yang K, Li Y, Kumamoto E, Furue H, Yoshimura M (2001) Voltage-clamp recordings of postsynaptic currents in substantia gelatinosa neurons in vitro and its applications to assess synaptic transmission. Brain Res Brain Res Protoc 7:235-240.

Zhang C, Restrepo D (2003) Heterogeneous expression of connexin 36 in the olfactory epithelium and glomerular layer of the olfactory bulb. J Comp Neurol 459:426-439. 